\title{
Thinking About the Political Impacts of the Electoral College ${ }^{\dagger}$
}

\author{
BERNARD GROFMAN ${ }^{1, *}$ and SCOTT L. FELD ${ }^{2}$ \\ ${ }^{1}$ School of Social Sciences, University of California, Irvine, California 92697; ${ }^{2}$ Department of Sociology, \\ Purdue University \\ ("Author for correspondence: e-mail: BGrofman@uci.edu)
}

After most U.S. presidential elections there are calls for passage of a constitutional amendment to modify the state-wide winner-take-all feature of the Electoral College currently found in all but two states, ${ }^{1}$ The two most frequent proposals are (1) to replace the Electoral College with direct popular elections, ${ }^{2}$ and (2) to have electoral college seats allocated at the level of House districts, with a two seat bonus to the state-wide winner - the rule now in place in Nebraska in Maine. ${ }^{3}$

Those who wish to eliminate or substantially modify the Electoral College, usually begin by noting that the original justification for its existence, the designation of sets of knowledgeable individuals who will meet in isolation in their respective states to deliberate and to make informed choices, has zero relevance to the modern world. Opponents also commonly point to two key problems: (a) the failure of the Electoral College to satisfy the "one person, one vote" standard because of its overweighting of the seat shares of the smaller states, ${ }^{4}$ and (b) the potential for the winner of the Electoral College majority to be a popular vote loser. In addition, and relatedly, (c) it has been argued that one party may develop a "built-in" advantage in the Electoral College if its strength comes disproportionately from the smaller states. ${ }^{5}$

A further pair of increasingly heard interlinked arguments against the Electoral College are that (d) the Electoral College focuses candidate attention only on the relative handful of potentially competitive states, leaving much of the country barely aware that a presidential election is going on, and thus reducing overall incentives for turnout, and (e) that it unduly raises the importance of issues that are of concern to voters in the competitive states relative to the issues of concern to voters whose states are not "in play." A sixth argument against the present Electoral College arrangements is that (f) since we might expect that the outcome in the most competitive state(s) will be more competitive than the national popular vote outcome, and since the outcome of a close

\footnotetext{
${ }^{\dagger}$ The senior author is indebted to helpful conversations over the years with Guillermo Owen about the topics discussed in this paper and to a recent conversation with Alan Natapoff. Errors remaining are solely the responsibility of the authors.
} 
election in even a single (large) state may be decisive in the Electoral College, the incentives for practicing electoral fraud in such states are considerable. ${ }^{6}$

On the other hand, the Electoral College has not been without its defenders, who suggest that the Electoral College, while no longer serving the purposes intended by the Founding Fathers, has evolved to play new and useful roles. These defenders minimize the importance of the arguments against the Electoral College and/or stand these arguments on their head to make them appear supportive of the status quo, and they also introduce one key new argument of their own, having to do with the role of the Electoral College in fostering a two-party system. ${ }^{7}$

Regarding the failure of the Electoral College to satisfy the "one person, one vote," there are two common rejoinders by defenders of the present arrangements. First is the remark that the U.S. is not a pure democracy in that its institutions deliberately balance state-specific representation with the representation of individuals. This rejoinder is sometimes stated in the form that "It makes no sense to object to the Electoral College unless you are also willing to reject the bicameral congress, since it is state representation in the U.S. Senate that creates the (supposed) small state bias in the Electoral College." A second type of response to the claim of a small state bias in the Electoral College is that the magnitude of this bias is greatly overstated. Indeed, the argument is frequently made by academics versed in game theory that it is actually voters in large states, not small states, who are actually overrepresented in the Electoral College, because large states have a much greater chance to be pivotal. ${ }^{8}$ Because of their views about pivotal power in the Electoral College favoring the larger states, some scholars have suggested that we may need to reweight the states to give even more weight to the smaller states (Natapoff 2004). In particular, arguments whose assumptions we discuss later suggest that, for equity reasons, we should assign weights to each state that are proportional to the square root of the state's population, thus reducing the representation of the larger states (Felsenthal \& Machover, 1998).

Regarding the possibility that the Electoral College may award victory to a candidate with fewer popular votes than his opponent(s), there are two responses. The first is that the claim that is outcome has been relatively rare, and will continue to be rare. ${ }^{9}$ The second is that, even when such a divergence does occur - and, of course, once Florida was definitively counted for Bush, the "worst case scenario" of a popular vote loser coming in with an Electoral College majority did happen in $2000,{ }^{10}$ it is still not something to get very upset about. Indeed, the agitation for reform of the Electoral College after the 2000 election was surprisingly limited, largely confined to pundits, talk show hosts, and political science and law professors. While the disputed vote in Florida led to a concern about who had legitimately won the Electoral College, most ordinary Americans seemed to have no trouble accepting the notion that the winner of the Electoral College vote was entitled to be president 
even if some other candidate had won more individual votes. An analogy was sometimes made to the World Series, where the winner was the team winning four of seven games, and not the team that had batted in the most runs overall. ${ }^{11}$

Regarding the claim that there is a significant Republican bias in the Electoral College, defenders of the Electoral College must admit that, in 2000, had there not been a two-seat bonus for senatorial seats, ${ }^{12}$ even with a Bush victory in Florida, a 435 seat Electoral College (without D.C.) would have elected Gore by a margin of 224-211(51.9\%), while a 436 seat Electoral College (with D.C.) would have elected Gore by a margin of 225-211(51.6\%) which was used to argue that that the Electoral College now has a (small) built in-bias toward the Republicans based solely on greater Republican strength in the smaller states. But we would not want to overgeneralize the implications of what happened in 2000. In 2004, we find that Bush would have won a majority of a 435 seat Electoral College in 2004 even without the two-seat Senate "bonus" (218-217), while if we throw in the District of Columbia to form a 436 seat Electoral College, then we get a tie. ${ }^{13}$

Moreover, a change of outcomes in any one of several relatively close states would have changed our perceptions of a pro-Republican bias in the Electoral College in both 2000 and 2004. And, more sophisticated analyses, based on Tufte's (1973) method of calculating electoral responsiveness (a.k.a. swing ratio) and partisan bias suggest that the observed pro-Republican bias in 2000 is induced less by the overweighting of the smaller states, than by the distribution of the Nader vote. With the Nader vote taken as given we find a statistically significant (but substantively quite small) pro-Republican bias in the Electoral College in 2000; but when we imagine a world without a Nader candidacy and reallocate the Nader vote in a plausible fashion to the two major party candidates (allowing for some Nader voters to drop out of the election), then we find a very small and not statistically significant pro-Democratic bias in the Electoral College in 2000. ${ }^{14}$

As for the claim that the nature of the Electoral College focuses the attention of presidential candidates primarily on a relative handful of potentially competitive states, ${ }^{15}$ for anyone who watched the news in the last month or so of the 2004 presidential campaign it seems hard to disagree with this observation. ${ }^{16}$ But even if it is true, one must ask whether methods that might replace the present Electoral College might not have equally problematic implications for the nature of presidential campaigning, e.g., by focusing campaigning on the largest media markets where the greatest bang for the buck might be had in locating voters to persuade/mobilize to go to the polls (Kimberling, 2004). And when we turn to the claim that the concerns of voters in the competitive states are overweighted relative to the concerns of voters in states not in play, a natural rejoinder is to point out that, if the voters in the latter group of states were bothered by their lack of impact, the threat to behave in a less predictable 
attention might seem sufficient to restore some or all of their influence by making them less taken for granted. And perhaps even more importantly, it seems there is a tension that needs to be resolved between the claim that the Electoral College benefits small states (or large states, for that matter) and the claim that the Electoral College benefits voters in competitive states, since the two sets of categories may be uncorrelated. ${ }^{17}$

As for the incentives to election fraud argument, we can agree with its force, but ask "Would the alternatives to the present arrangements be any better?" In particular, opponents of change in the Electoral College point out that if we switched to a popular vote, there is the potential nightmare in a close race for the popular vote of there being simultaneous lawsuits in multiple states. The votes sought might not affect outcomes in any of the states, individually, but collectively, could switch the popular vote outcome. Thus, replacing the Electoral College with direct elections could lead us from a recurrent but limited problem with recounting close votes confined to one or at most a handful of states to an almost certainly less frequent, but potentially far more troubling, nationwide recount struggle.

Finally, defenders of the Electoral College point to what they see as its key role as a prop for two-party competition and the maintenance of decisive election outcomes that do not require a second stage of voting in the Congress. ${ }^{18}$ They suggest that the winner-take-all feature of the Electoral College tends to reinforce two-partyism by making it less likely that the presence of minor party candidates will prevent there being a clear Electoral College winner from one of the major parties - e.g., a Nader may gain nearly $3 \%$ of the national vote, ${ }^{19}$ or a Perot $8.4 \%$ (1996) or even $19.4 \%$ (1992) without forcing the presidential election to be decided by the U.S. House, because the popular vote share of these minor party candidates does not translate into Electoral College votes..$^{20}$ On the other hand, were we to switch to direct elections, minor parties might have even stronger incentives to (threaten to) run candidates so as to force the election into the House, and thus be able to "blackmail" the major parties into accepting some extremist points of view, making particular judicial or other appointments, or funding particular kinds of pork-barrel projects. ${ }^{21}$

While proponents of changing the Electoral College, like Edwards (2004: 135-142), have argued that the role of the Electoral College in reinforcing two-partyism has been greatly exaggerated, in that two-party competition at the local level may spring simply from plurality-based elections in singlemember districts (Duverger, 1959; cf. Cox, 1997), we would note that virtually the only country in the world with a true and durable two-party system at the national level is the U.S. (Gaines, 1999). And if it is not a presidential form of government in conjunction with the Electoral College that is keeping the U.S. so firmly on a two-party track nationally, it is hard to see what other plausible explanation there might be for this long-run phenomenon. ${ }^{22}$ 
While we heard quite a bit about the need for Electoral College reform after the 2000 presidential election (especially from Democrats, who were often quite vociferous on the topic), and would probably have heard even more after the 2004 election if there again had been a disagreement between the two types of winners, the concordance in 2004 between Electoral College and popular vote winners appears to have effectively taken this issue off the political agenda - at least for the moment. Nonetheless the issues for democratic theory raised in the debate over the Electoral College remain very important ones, and we believe this is an area where Public Choice insights into the modeling of voting processes can make a contribution.

Accordingly, in the remainder of this essay we turn to a somewhat more detailed discussion of two of the issues mentioned earlier. ${ }^{23}$ We summarize our own recent work on weighted voting games and show how it might be applied to the Electoral College to understand the nature of small versus large state biases, on the one hand, and the implications for campaign strategies of the interaction between a state's political competitiveness and its size (in terms of EC votes), on the other. We show how our results lead us to a multiplicative model of optimal campaign investment.at the state level.

\section{A Multiplicative Model of Optimal Campaign Investment at the State Level in Presidential Campaigning Under the Electoral College}

\subsection{Small State Bias in the Electoral College}

We can define a majority rule weighted voting game in terms of its set of winning coalitions, such that when we assign voters weight $q_{i}$, with $\sum q_{i}=$ $N$, a winning coalition is one the sum of whose weights exceeds $\mathrm{N} / 2$. The Electoral College specifies a majority rule weighted vote game, with the $q_{i}$ values given by each state's number of votes in the Electoral College. The classic works on the magnitude of small-state bias in the Electoral College are Shapley and Mann (1962) and Owen (1975), which make use of the notion of pivotal power in such a game. An actor in a (majority rule) weighted vote game is pivotal in the sense of Shapley-Shubik when that single actor's addition to a previously losing coalition of voters turns that losing coalition into a winning coalition were the actor to vote YES. ${ }^{24}$

We can model the power of a state as the proportion of time that that state will be pivotal in the Electoral College when we treat all permutations of the states as equally likely and assume that states vote (YES) one at a time in the order listed in the permutation. ${ }^{25}$ Because there are two competing effects at the level of whole states which go in opposite directions, the Electoral College overrepresentation of state's relative to their population, on the one hand, and the enhanced a priori likelihood that large states will be pivotal in the Electoral 
College, on the other, Owen finds that, using states as our units, biases in favor of small state are much less than one might think when one looks at a priori power, since he finds a ratio of share of pivotal power to Electoral College share that is very close to one for all states, although slightly above one for the larger states (states that in 1970 had 21 or more Electoral College votes: compare columns 1 and 4 in Owen, Table 1, p. 949). For the largest state, California, the 1970 ratio of a priori Shapley-Shubik pivotal power to EC votes was $1.056(=47.51 / 45)$, while the states with $3 \mathrm{EC}$ votes had a ratio of $.9973(=2.992 / 3)$.

It is obvious that, the larger the size of a state's Electoral College vote share, the more often will the state be pivotal, but we can also easily find examples in which a state's Shapley-Shubik value will not be linear with a state's Electoral College weighting. Consider, for example, the weighted vote game with three players where two have weight four and one has weight one. If five votes are needed to win, then all three players have an equal chance of being pivotal, and thus each has equal power according to the Shapley-Shubik value (as well as according to other power scores such as the Banzhaf index). Nonetheless, when the number of actors in a (majority rule) weighted voting game is relatively large $(>30)$ and the distribution of weights is relatively smooth (i.e., we do not have a very large number of very small actors and only a handful of very large ones, or conversely) an appeal to the law of large numbers suggests that Shapley-Shubik values will be approximately linear with weights (Feld \& Grofman, 2005; cf. Lindner \& Machover, 2004). A "quick and dirty" check on smoothness comes by comparing the size of the largest and the smallest minimum winning coalition in a weighted voting game. If these are not too far apart then, for relatively large-scale voting games, taking Shapley-Shubik values to be the weights themselves will be a reasonably good approximation.

However, since the same game can be represented with more than one set of weights, ${ }^{26}$ if we are trying to decide how smooth a game is, we really need to find the equivalent representation of the game in which the discrepancy between largest and smallest coalition is minimized. ${ }^{27}$ Still, as a first cut, we can look at the discrepancy between smallest and largest minimal wining coalition for the actual weights, since that gives us an upper bound on smoothness. ${ }^{28}$ For the U.S. Electoral College in 2004, the largest minimal wining coalition is 281 ; while the smallest minimal winning coalition is 270 votes. This is a pretty small discrepancy - on the order of magnitude of 4 percent. Similarly, in 2000, the largest minimal wining coalition was 280; while the smallest minimal winning coalition was again 270 votes. Thus, with 50 states plus the District of Columbia, and a relatively smooth distribution, we would expect that Electoral College weights and Shapley-Shubik values should not be that far apart. And this is, of course, exactly what Owen (1975) found in 1970 for Shapley-Shubik values. ${ }^{29}$ 
The Electoral College power of a voter in a given state is given by the probability that s/he will be pivotal in the state multiplied by the probability that that state will be pivotal in the Electoral College (Owen, 1975; Gelman, Katz, \& Bafumi, 2004), under the assumption that these are independent events. For voters, the standard result, for a most often used type of random voting model, is that the a priori likelihood a voter will be pivotal in his/her state is proportional to the square root of the state's voting population. ${ }^{30}$ If we simplify by assuming that each state's share of House seats is given by the state's population (neglecting disproportionalities caused by lumpiness effects and the fact that each state is guaranteed at least one House seat regardless of its population), and also assume that the probability that a state will be pivotal in the Electoral College is roughly linear with the state's Electoral College votes $(\mathrm{E})$, then the a priori power of an individual voter in any given state to affect Electoral College outcomes will be roughly proportional to $\frac{E}{\sqrt{E-2}}$.

If we look, then, at the combined power of the voters in any given state, if the probability of a single voter being pivotal in the voter's own state is inversely proportional to the square root of the size of the state, then the $a$ priori combined power of the state's voters will be roughly proportional to $\frac{E(E-2)}{\sqrt{E-2}}=E \sqrt{E-2}$ This analysis leads us to expect that voters in large states would be substantially advantaged in terms of expected a priori power.

However, other work (Good \& Meyer, 1975; Chamberlain \& Rothschild, 1982; Gelman, Katz, \& Bafumi, 2004) has called into question the assumption that a voter's pivotal power in her own state will fall off with the square root of the state population. Based both on a more complex set of probabilistic assumptions in these papers, and the extensive empirical investigations in Gelman, Katz, and Bafumi (2004), it now appears more reasonable to expect that an individual voter's pivotal power in her state will simply be roughly inversely proportional to the size of the state. Under this assumption, and continuing our previous assumption that state level power is roughly proportional to E, we would now have a given voter's a priori likelihood of influencing the Electoral College as roughly proportional to $\frac{E}{E-2}$. Thus, if we replace the assumption that each a voter in a state of size $\mathrm{n}$ has a probability of being decisive in that state that is inverse to the square root of $n$ with the linearity assumption of Gelman, Katz, and Bafumi (2004), then we get the result that the combined a priori power of voters in a given state to influence Electoral College outcomes is presently roughly proportional to $\frac{E(E-2)}{E-2}=E$. In other words, under these assumptions, voter's have power proportional to their state's Electoral College vote regardless of the size of the state in which they live. An identical result, but under a bargaining theory model of market power rather than the pivotal power ideas of the standard power score literature, is reached by Feld and Grofman (2005). 
Under the first assumption, that a voter's power to be decisive in a given state is inversely proportional to the square state's population, then, in order to assure that all voters are assigned equal power, we should assign weights to the states that are proportional to the square root of the state's population, since so doing will result in each state's voters having combined pivotal power directly proportional to their numbers (Felsenthal \& Machover, 1998). In contrast, under the second assumption, that a voter's power to be decisive in a given state is inversely proportional to the state's population, if we wish to improve equity, we should simply allocate Electoral College seats according to population (or, to keep it even simpler, according to a state's representation in the U.S House of Representatives). Thus, which model we use has crucial implications for what normative recommendations about Electoral College reform might seem to make most sense. ${ }^{31}$ Which model we use also turns out to have crucial empirical implications for our expectations about candidate campaigning behavior.

\subsection{The Impact of Electoral College Weightings on the Choices Candidates Make About How Much Time and Money to Spend in/on Each State}

Let us posit that campaigners invest resources in influencing voters so as to equalize the expected marginal gain in the probability of their winning the Electoral College.

\subsection{Abstracting Away from Competitiveness Considerations}

First we shall consider what happens when campaigners have no advance knowledge about the degree of competitiveness to be expected in any given state.

From the results given above under the assumption that a priori voter power in a given state is inversely proportional to the square root of the state's population, we see that, if we neglect the differences in competitiveness across states, and the further complexities caused by size and cost differences in media markets, etc., we might expect that candidates who wished to maximize their chances of winning an Electoral College majority would allocate their campaign time and resources roughly proportional to the 3/2ths power of the state's population. This would mean that, ceteris paribus, disproportionately more time would be spent in/on the largest states. This intriguing result is first given by Brams and Davis (1974). On the other hand, if we replace the assumption that each a voter in a state of size $n$ has a probability of being decisive in that state that is inverse to the square root of $n$ with the linearity assumption of Gelman, Katz, and Bafumi (2004), then, since the combined a priori power of voters in a given state to influence Electoral College outcomes is roughly proportional to $\mathrm{E}$, under our revised assumptions, we would 
expect that, ceteris paribus, campaigning time and resources would be allocated to each state directly proportional to the state's Electoral College seat share.

Data has been compiled by Daron Shaw (2003: reported in Edwards, 2004: Table 5.2,104-105) on visits by major party presidential and vice-presidential candidates during the post-convention period in 2000 . When we look at that data, and focus on presidential visits (excluding vacation travel), we find that both the size of a state's Electoral College share and the 3/2ths power of that share EC share can each help explain a little over one-third of the variation in the observed pattern of visits, but the linear effect is the stronger of the two, explaining nearly $40 \%$ of the variance; furthermore, when both variables are entered into the same regression, only the linear effect is statistically significant. Thus, the data on campaign investments appear consistent with the earlier empirical work of Colantoni, Levesque, and Ordeshook (1975) and expectations derived from the work of Gelman, Katz, and Bafumi (2004), as well as with an implication that can be derived from our own previous work on the "market value" of voters (Feld \& Grofman, 2005). ${ }^{32}$

\subsection{Building in Variation in Competition Levels}

However, EC vote share alone should not be expected to perfectly predict investment decisions since, in the real world, not only it is the case that candidates may visit states to help other candidates or for speaking occasions that might get national publicity, but also it is never the case that presidential candidates are without some knowledge of the propensities of states to vote Republican or Democratic at the presidential level. If we continue to posit that campaigners invest resources in influencing voters in such a way as to equalize the marginal gain in the probability of their winning the Electoral College, we can again predict that investment in a state will, ceteris paribus, be proportional to the combined power of voters in that state to change the Electoral College outcome; but now this value will be given by:

(1) the probability that a voter in a given state will be pivotal in their state, multiplied by,

(2) the number of voters in the state, multiplied by,

(3) the probability that that state will be pivotal in the Electoral College.

Moreover, introducing variation in state level political competitiveness affects our calculations of both the first and the third multiplicand. For the first factor, it puts the emphasis on the behavior of undecided (or potentially switchable) voters. For the third factor it changes our focus from the overall weighted voting game to what we may call the derived voting game, i.e., the game defined by the probabilistic assessment of feasible outcomes. 
To model competition we:

(a) assume that each state has a known triple of estimated vote shares $(d, r$, $u$ ) for the two major party candidates, with $d+r+u=1$, such that we may take $d$ and $r$ to be voters who have already decided and $u$ to be the proportion of the as yet undecided voters.

(b) further simplify by assuming that the only way in which persuasive investment can change the outcome in a state is by transforming some of the previously undecided voters into voters for a given party. ${ }^{33}$

(c) posit some function $v_{i}(d, r, u, x)$, where $\mathrm{x}$ is the amount of additional resources invested in the state in voter persuasion efforts, and where $\Delta v_{i} / \Delta x$ that gives the marginal gain in the probability that the ith candidate will capture the state given that additional investment of $x$.

(d) further simplify by assuming that $\Delta v_{i} / \Delta x$ exhibits diminishing marginal product.

Under these assumptions, once we specify particular functional forms, we can define a well-defined decision-theoretic optimization problem that can be solved either analytically or by simulation. But rather than trying to solve that problem under specified assumptions, here we simply note some obvious implications of setting up the problem this way that should hold for any plausible model of the persuasion process. ${ }^{34}$

\subsection{Re the First Multiplicand}

First and foremost, it is apparent that if either $d$ or $r$ is greater than one-half, then the first multiplicand, which taps the pivotal power or market value of undecided voters in a state, will be zero for both parties. Thus, once a state is firmly and irrevocably in one's own hands, or firmly or irrevocably in the hands of one's opponent, it makes no sense to invest further campaign resources in that state.

Second, ceteris paribus, the closer the state, the more resources per undecided voter will be invested there. Or, to put it in a way familiar to those who read newspaper coverage of recent U.S. presidential elections there are going to be "battleground states" which are the focus of most of the candidate attention and money. ${ }^{35}$

Third, for a fixed $u$, if candidate's have equal capital to spend, if neither candidate's reliable vote share is above .5 , ceteris paribus, the candidate who is closer is to .5 will generally spend more money in the state than the candidate who is behind. Thus, ceteris paribus, where outcomes are not certain, candidates will invest proportionally more where their chances are better. 


\subsection{Re the Third Multiplicand}

The critical impact of taking competitiveness into account is that a state's pivotal power is now based on a probabilistic weighted voting game, where pivotal power must be discounted for by the probability that any particular combination of votes in which the given candidate carries the state will occur. ${ }^{36}$ This has important implications.

First and most obviously, once there are states where either $d$ or $r$ is greater than one-half with probability one, i.e., states that are no longer "in play," to calculate the pivotal power of the remaining states, we must look at the reduced weighting voting game where the Electoral College votes from the already decided states are treated as given. In doing so, calculations of the pivotal value of the remaining states will almost certainly change, and they may even change dramatically. Consider for example, the situation at 9 am the day after the 2004 election, with three states, New Mexico (five votes), Iowa (7 votes) and Ohio (20 votes) still regarded by CNN as too close to call, and with 254 EC votes definitively assigned to Bush and 252 to Kerry. The outcomes in New Mexico and Iowa were, at this point, irrelevant. Only Ohio mattered, since only Ohio's Electoral College votes were large enough to shift a candidate (either candidate) into the winner's circle with 270 or more EC votes.

Now imagine that this had been the situation prior to the Tuesday voting. In the reduced Electoral College weighted voting game, where only 32 votes were at play, and Bush needed 16 to win and Kerry needed 18 to win, it is apparent that only Ohio could be pivotal. Here, Iowa and New Mexico are reduced to the status of what game theorists call dummies, i.e., players that are not part of any minimal winning coalition. Under these circumstances (assuming away uncertainties about the other states), it would make sense for a candidate to spend all his (remaining) time and money in/on Ohio! The undecided voters in the other two states are simply not worth trying to persuade.

Second, and more generally, we should calculate each state's pivotal power as the probability that a state will be pivotal in any given permutation of the states multiplied by the probability that that permutation (or combination) will occur. ${ }^{37}$

Taking the two sets of points together, we see that investment strategies (a) will be expected to vary over time as political competition changes, and (b) that changes in competition will affect both the calculation of the power of the undecided voters within any given state to affect the overall Electoral College outcome, and the likelihood that any given state will be pivotal in the new (probabilistically derived) Electoral College game. ${ }^{38}$ While all these points may well seem obvious, ${ }^{39}$ and something like the intuitions underlying them appear known to politicians and journalists and many political scientists who write about the Electoral College (see e.g., Edwards, 105-116); ${ }^{40}$ as far 
as we can tell, this is the first time anyone has ever written them down the key implications and intuitions in a reasonably precise fashion. ${ }^{41}$ And getting these intuitions right is very relevant to the seemingly never-ending debate about the desirability of Electoral College reform.

Just as we previously tested the commonsense proposition that states with greater EC weights would be more likely to be visited by presidential candidates - and found confirmation for that proposition, our more complex model (taking uncertainty into account) would lead us to expect that states with greater competitiveness about outcome would be more likely to be visited by presidential candidates. Using the absolute value of the difference between the winner and runner-up's shares of the two-party vote as a (posterior) first cut at measuring a state's competitiveness we find this variable, standing alone, to be able to explain about $21 \%$ of the variation in the statewide pattern of presidential candidates' campaign visits in 2000. Putting EC seat share and margin of victory into the same regression in an additive fashion, we are now able to explain over $53 \%$ of the variation in the statewide pattern of presidential candidates' campaign visits.

However, our approach also, and somewhat less intuitively, suggests that we ought to try to fit a multiplicative model, involving EC weights multiplied by state marginality. When we do so, we are able to explain $69 \%$ of the variation. ${ }^{42}$ This seems to us to be very strong support for the intuitions underlying our model, since we would never expect a perfect fit, in that presidential candidate visits to a state also occur for reasons unconnected with the presidential campaign, per se, and because of further complications caused by transaction cost factors such as geographic propinquity and overlapping media markets that generate efficiencies in combining visits to particular states. ${ }^{43}$

\section{Discussion}

After reviewing the arguments pro and con the maintenance of the present Electoral College rules we find that the case against the Electoral College is far from clear, especially since we would trading an institution whose pluses and minuses we know for one whose evils are yet to be determined. Personally, this seems to us to argue on the side of caution. This preference is further reinforced when we consider the present state of Public Choice theory as to the effects of the present Electoral College arrangements. We simply haven't had models that do a good job in explaining/predicting how the Electoral College acts to structure incentives of voters, candidates and parties. Indeed, there simply is not consensus on the literature on some of the most important points, e.g., "Does the Electoral College give greater power to influence outcomes to citizens in small states or to citizens in large states?" How important is the Electoral College in reinforcing a two party system?" 
"Which states will attract the most attention during a campaign?" If, with the advantage of 200 or so years of data on how an institution operates, we cannot agree on what it does, we must express even greater skepticism about our ability to predict what some new institution for electing the president will do. ${ }^{44}$

Of course, any theoretical debate is largely moot. First, given the uncertainties about how the Electoral System operates and what would happen if we tinker with it, representatives of large states, who see themselves as benefiting from voting under the unit rule, are unlikely to favor change; while representatives of small states, who see themselves as benefiting from the two-seat bonus, are also unlikely to favor change. Finally, while we might think that states that were not competitive might favor change so as to increase their importance in the calculations of presidential candidates, this seems dubious, since if we look at a long enough time period, most states have experienced at least one shift from being solidly Democratic to being solidly Republican at the presidential level, or have gone in the other direction, and virtually every state in the U.S. has been competitive at some point in its history (even if only briefly). ${ }^{45}$ Second, and perhaps even more importantly, the incentives to change the institution tend to fade fast after an election, as those who won become reluctant to give up what they now come to regard as a winning formula. Thus, we expect that the Electoral College will be with us for a long time to come.

\section{Notes}

1. Winner-take-all was not always the standard way for a state to allocate Electoral College votes, but once we had the development of a two-party system, there were strong incentives for a state's dominant party to wish to maximize the impact of their state's voters in determining the presidential outcome. As more states adopted a winner-take-all allocation rule, the remaining states generally followed suit out of self-defense, lest internal divisions reduce the state's overall impact on outcomes. (In the words of James Madison (in a letter to George Hay, August 23, 1823; cited in Farrand, 1966, Vol. 3, p. 459): states opted for winner-take-all "as the only expedient for baffling the policy of the particular States which had set the example.") It might thus appear that having all states using a winner-take-all rule was an equilibrium outcome, and it appeared that way for some time, but Michigan in 1892 temporarily opted for splitting its vote in a year when the party winning the Electoral College majority and the party in control of the state legislature were not the same. That decision was temporary, but Nebraska switched permanently in 1969, and Maine in 1991, to methods that could result in each state's Electoral College votes being divided among two or more candidates.

2. Sometimes such proposals maintain the present requirement of a $50 \%$ vote share to the winner to forestall the need for a runoff election to be decided by the U.S. House of Representatives, and sometimes they allow for election by simple plurality of the popular vote, thus obviating the need for runoffs; and sometimes they propose an intermediate threshold, such as $40 \%$ (see Edwards, 2004). Each of these alternatives raises new problems of its own, the discussion of which, for space reasons, we will largely omit. 
3. In 2004 there was an initiative on the ballot in Colorado to replace winner-take-all Electoral College allocation rules in that state with Maine/Nebraska procedure. That initiative failed.

4. Recall that each state receives a number of electoral college votes that equals the number of Representatives the state has in the U.S. House of Representatives, plus two (the size of the state's representation in the U.S. Senate). This allocation rule was part of a political compromise between large and small state representatives at the constitutional convention.

5. Of course, even if there were no overweighting of the smaller states, we could still have a discrepancy between the popular vote winner and the winner of the Electoral College majority. Indeed, this possibility exists even if all states have the same number of Electoral College seats. Consider, for example, a country with three equipopulous states, each awarded three Electoral College votes. In two of the states the Democrats win by a 60 40 margin; in the third, the Republican wins 80-20. Assuming equal levels of turnout across states, we have the Republican candidate with $53.3 \%$ of the popular vote, but losing the Electoral College vote by 2-1. (The alert reader will recognize this example as one commonly used to illustrate the concept of gerrymandering.) Another way in which a party might be disadvantaged in the Electoral College occurs when minor party candidates operate disproportionately to its disadvantage.

6. Also, if the Electoral College vote is close, then there may be attempted bribery of individual electors to induce them to vote for someone other than the person to whom their slate was pledged. We neglect this issue in the discussion that follows since it can easily be remedied by eliminating the "physical" electors and replacing them with a mechanical tally of the EC votes received by a given state slate - a change in rules that virtually everyone would endorse, but which has not happened because of the difficulty of making constitutional amendments and the way in which the issue of "faithless electors" is bound up in broader discussions of reform of the Electoral College.

7. Other arguments raised that, for reasons of space, we will not bother to deal with include the supposed roles of the Electoral College in reinforcing federalism, and in creating the illusion of a presidential mandate (see Edwards, 2004, Chap. 6).

8. Pivotal power is usually defined in terms of either the Banzhaf index or the Shapley-Shubik value (see Owen, 1995 for definitions.)

9. During the modern era where presidential electors are chosen by popular vote rather than by the state legislature there are three occasions of divergence between EC and popular vote winners: 1876, 1888, and 2000 - although the "true" popular vote tallies in 1876 are matter of dispute (Kimberling 2004), and some scholars say that 1960 should also be counted as involving a divergence between popular vote winner and EC winner if, as seems reasonable, one does not count votes for the slate of unpledged Democratic electors in Alabama as votes for Kennedy, because these electors would not have voted for him in the Electoral College (Edwards, 2004: 48-51). There were expectations that 2004 would also see such a discrepancy between Electoral College and popular vote winners. Before a Democratic nominee was named, it was thought that if this scenario occurred in 2004 it would be because Bush would win the Electoral College but lose the popular vote. In the months after Kerry's nomination, however, web-sites following the election polls begin switching their views, suggesting that Bush was doing better in the popular vote than he was projected to do in the Electoral College. Of course, as it turned out, Bush won both a popular and an Electoral College majority in 2004, and won a marginally higher share of the Electoral College vote (53.2\%) than of the popular vote.

10. However, thanks to Nader's spoiler role, Gore did not receive a majority of the popular vote in 2000.

11. This is not to say that Americans would prefer the Electoral College to a direct vote. When the choice is posed in terms of whether or not it is best to select the candidate 
with the most votes or to continue the present Electoral College arrangements, most Americans prefer direct elections (Edwards, 2004).

12. Or, for D.C., what we might call "pseudo-senatorial" seats.

13. Because of the fact that, in toto, the states that Bush won in 2000 gained 11 seats in the 2001 reapportionment and lost only 4 seats, it was expected that a pro-Republican bias in the Republican advantage in the Electoral College would be further exacerbated in 2004 by 7 seats.

14. More detailed analyses and calculations done by one of the present authors (Grofman) are omitted for space reasons. Suffice it to note that, in 2000, there was not a statistically significant correlation between the number of Electoral College seats in a state and Bush's share of the two party vote.

15. Of course, we must be careful to recognize that presidential candidates visit states for reasons besides a desire to pick up votes for themselves.

16. As a resident of California one of the present authors can also attest that the 2004 presidential contest largely bypassed that state.

17. In fact, in 2000 , for example, there was not a statistically significant correlation between the number of Electoral College seats in a state and the absolute magnitude of the victory margin in the state. (An informal attempt to integrate the roles of state size and state competitiveness in shaping presidential candidate campaign strategies is at the heart of the last part of this essay).

18. Note that the 2000 election controversy did not involve the possibility of a runoff. Whoever was given Florida's EC votes won the presidency. Note also that, if we implement direct elections and then only require simple plurality to win, this brings with it an enhanced likelihood of failing to elect Condorcet winners (and even the possibility of electing Condorcet losers); while if we shift to new types of runoff methods these bring with them potential complications in terms, for example, of incentives for party proliferation.

19. In 2000 , minor party candidates captured nearly $4 \%$ of the vote.

20. Candidates from sectional parties, like the Dixiecrats in 1948, can pick up Electoral College seats, but it seems to us unlikely that even this type of minor party would succeed in denying all other candidates an Electoral College majority unless they were at the same time successful in denying all other candidates a popular vote majority.

21. Even under the present Electoral College arrangements we have examples of such blackmail plots, e.g., by unpledged Democratic electors from Alabama and Mississippi in 1960 (Edwards, 2004: 64-67). But we would expect a greater blackmail potential from political groupings that are not geographically concentrated under a direct election method than under the present system.

22. In the U.S., there are now collusive rules to perpetuate the two-party system, e.g., by making it hard for other than the two major parties to get on the ballot, and to constrain presidential debates to the major parties, but these rules cannot explain creation of two national parties in the first place.

23. Earlier we had briefly referenced work by one of the present authors (Grofman) on the nature of partisan bias in 2000 .

24. Here, for simplicity of exposition, we neglect blocking power.

25. This is often referred to as an a priori measure of power. When we focus on permutations we are making use of the Shapley-Shubik measure; were we to focus on combinations of voting outcomes we would be in the realm of the Banzhaf index (Owen, 1995).

26. We can define two weighted voting games as equivalent when each gives rise to the same set of winning coalitions. Thus, the majority rule weighted voting game $(4,4,1)$, with five votes needed to win, is equivalent to the weighted vote game $(1,1,1)$ with two votes 
needed to win, and is also equivalent to the weighted vote game $(1 / 3,1 / 3,1 / 3)$ where a coalition with weight strictly more than $1 / 2$ is winning.

27. One of the present authors (Feld) has written a computer program to find this representation.

28. It is an upper bound since we might be able to find an equivalent set of weights which would reduce the discrepancy.

29. Similarly we would expect that, in the Electoral College weights and Banzhaf scores would not be that far apart. In 2000, Gelman, Katz and Bafumi (2004: 662) find that the discrepancy between Banzhaf scores and Electoral College weights is "less than $10 \%$ for all states."

30. See e.g., Banzhaf (1965), Owen and Grofman (1984). The alert reader will recognize this result as analogous to the way in which the standard error of the sampling distribution of the mean falls off inversely with the square root of the sample size and not inversely with the sample size itself.

31. Related to the dispute about the relative Electoral College power of voters in large and small states are arguments about how powerful are certain geographically concentrated blocs of voters relative to other voting blocs whose members are more geographically dispersed. For reasons of space we shall not discuss those arguments here.

32. This finding is generally consistent with the empirical analysis of Colantoni, Levesque, and Ordeshook (1975) for presidential campaigning in the 1950s and 1960s.

33. Thus, for simplicity of exposition, we neglect the possibility of the kinds of campaigning (perhaps highly negative) that might change the minds of previously committed voters. And we neglect turnout/mobilization issues.

34. To keep matters tractable, we are here treating the optimal investment problem as a decision-theoretic problem for a single candidate in a fixed environment. Ideally we would like to model this investment problem in game-theoretic terms, borrowing ideas from the literatures on vote-buying in legislatures (e.g., Snyder, 1991; Ansolabehere, Groseclose, \& Snyder, 1996, 2000) and on optimal campaign strategies (Colatoni, Levesque, \& Ordeshook, 1975), but that would take us into issues beyond the scope of this essay.

35. States can, however, over the course of a campaign, move in and out of the battleground category.

36. We previously referred to this as the probabilistically derived voting game.

37. If we were looking at Banzhaf scores rather than Shapley-Shubik values we would examine combinations rather than permutations. If there are enough states still in play, however, and there are no dummies, we may use the approximation that a state's undecided voters' market value is going to simply be roughly proportional to EC weight.

38. Thus, if all states were equally weighted then, ceteris paribus, only competitiveness would matter for investments. Imagine, for example, a majority rule Electoral College game, where there are only three states left undecided and any two of them will decide the election. If the three states have probabilities of $.40, .50$ and .60 of going Democratic, then, ceteris paribus, we might expect that the ratio of investments in any two states will be proportional to the ratio of the levels of uncertainty about the outcome in each state.

39. However, one less obvious conjecture is that lumpiness effects in terms of discrepancies between the size of the smallest and largest minimal winning coalitions will be greatest in the later stages of the presidential struggle as states are "taken off the board" for one party or another, implying that, in the later stages of presidential contests, we will probably see even more relative overconcentration of resources on the largest states still in play than was the case at the beginning. Some ideas that appear to be along similar lines are found in by Colantoni, Levesque and Ordeshook (1975:152). We do know that, in the 1960s, the second half of the presidential campaign saw contestation narrowed to a smaller set of states (Colantoni, Levesque, \& Ordeshook, 1975: Table 9, p. 151). 
40. For example, Edwards (2004: 113-114) quotes Douglas Bailey, who headed the advertising firm that handled Gerald Ford's, 1976 campaign as as saying that "those areas that you are sure to win or lose, you ignore."

41. Remarkably, as far as we can tell, the "state of the art" in the formal modeling literature on campaign strategies in the Electoral College remains the debate between Brams and Davis (1974) and Colantoni, Levesque, and Ordeshook (1975). In seeking to forecast campaign allocations to the states, the former does not explicitly model competitiveness; while the latter, although offering preliminary and abstract models with both size and competitiveness taken into account, does not elaborate fully on the commonsense implications of their ideas.

42. Because of multicollinearity issues the best-fitting model has two independent variables in it, $\mathrm{EC}$ and $\mathrm{EC}^{*}$ margin.

43. A natural extension of our model is to look at media attention during the campaign. Here we might expect that large states would attract national attention because of their perceived importance as audience for the major media, while close states would attract attention because of the media emphasis on the horse-race feature of campaigns, and because very close contests are more likely to be viewed as newsworthy. Again, we would expect that a model with a multiplicative component would fit best.

44. There is important work in the comparative politics and comparative political economy literature on the effects of alternative mechanisms for electing leaders worldwide (see e.g., Shugart \& Carey, 1992). As far as we can tell, however, that work has had zero impact on the U.S. debate about reforming or abolishing the Electoral College. (Reviewing the implications of that work here would take us too far afield from the limited focus of this essay.)

45. For example, California, which was not in play in the U.S. presidential contest of 2004, was viewed as in play for at least part of the 2000 presidential campaign, and might be back in play in the future if the Republican party makes further inroads into the Hispanic vote.

\section{References}

Banzhaf, J. F. III. (1965). Weighted voting doesn't work: A mathematical analysis. Rutgers Law Review, 19, 317-343.

Brams, S. J., \& Davis, M. (March 1974). The 3/2ths rule in presidential campaigning. American Political Science Review, 68, 113-134.

Chamberlain, G., \& Rothschild, M. (1981). A note on the probability of casting a decisive vote. Jounrnal of Economic Theory, 25, 152-162.

Cox, G. W. (1997). Making Votes Count: Strategic Coordination in the World's Electoral Systems. New York and London: Cambridge University Press.

Duverger, M. (1959). Political Parties: Their Organization and Activity in the Modern State. London, Methuen New York: Wiley.

Edwards, G. C. III. (2004). Why the Electoral College is Bad for America. New Haven, Connecticut. Yale University Press.

Feld, S. L., \& Grofman, B. (2005). Market Value in Weighted Voting Games. Paper prepared for delivery at the Annual Meeting of the Southern Political Science Association. New Orleans, February 7-9.

Felsenthal, D., \& Machover, M. (1998). The Measurement of Voting Power. Theory and Practice, Problems and Paradoxes. Northampton, Massachusetts: Edward Elgar.

Gaines, B. (1999). Duverger's law and the meaning of Canadian exceptionalism. Comparative Political. Studies, 32(7), 835-861.

Gelman, A., Katz, J., \& Bafumi, J. (2004). Standard voting power indexes do not work: An empirical analysis. British Journal of Political Science, 34, 657-674. 
Good, I. J., \& Meyer, L. S. (1975). Estimating the efficancy of a vote. Behavioral Science, 20, 25-33.

Groseclose, T., \& Snyder, J. M. Jr. (1996). Buying supermajorities. American Political Science Review, 90, 303-315.

Groseclose, T., \& Snyder, J. M. Jr. (2000). Vote buying, supermajorities, and flooded coalitions. American Political Science Review, 94, 683-684.

Gurk, H. M., \& Isbell, J. R. (1959). Simple solutions. In A. W. Tucker \& R. D. Luce (eds.), Contributions to the Theory of Games, Volume 4. Princeton, NJ: Princeton University Press, pp. 247-265.

Kimberling, W. C. (2004). The Electoral College. U.S. Federal Election Commission, Office of Election Administration.

Lindner, I., \& Machover, M. (2004). L. S. Penrose's limit theorem: Proof of some special cases. Mathematical Social Sciences, 47(1), 37-49.

Madison, J. (1823). Letter to John Hay, August 23, 1823. In Max Farrand (ed.), The Records of the Federal Convention of 1787 (rev. edition), Vol. 3. New Haven, Connecticut: Yale University Press, 1966, p. 459.

Natapoff, A. (2004). The Electoral College. Presentation to the Colloquium Series of the Institute for Mathematical Behavioral Sciences, University of California, Irvine, October.

Owen, G. (1975). Evaluation of a presidential election game. American Political Science Review, 69, 947-953.

Owen, G. (1995). Game Theory. San Diego, CA: Academic Press.

Owen, G., \& Grofman, B. (1984). To vote or not to vote: The paradox of nonvoting. Public Choice, 42, 311-325.

Shapley, L. S., \& Mann, I. (1962). Values of large games, VI: Evaluating the Electoral College exactly. RM-3158-PR. The RAND Corporation, May.

Shaw, D. (2003). A simple game: Uncovering Campaign Effects in the 2000 Presidential Election. Unpublished manuscript, Department of Political Science, University of Texas, Austin, July.

Shugart, M. S., \& Carey, J. M. (1992). Presidents and Assemblies: Constitutional Design and Electoral Dynamics. New York; Cambridge University Press.

Snyder, J. (1991). On buying legislatures. Economics and Politics, 3, 93-109.

Tufte, E. (1973). The relationship between seats and votes in two-party systems. The American Political Science Review, 67(2), 540-554. 